\title{
Subclinical interstitial lung damage in workers exposed to indium compounds
}

\author{
Sungyeul Choi ${ }^{1}$, Yong-Lim Won ${ }^{1}$, Dohyung Kim ${ }^{1}$, Gwang-Yong Yi ${ }^{1}$, Jai-Soung Park ${ }^{2}$ and Eun-A Kim ${ }^{1 *}$
}

\begin{abstract}
Objectives: The present study was designed to determine whether there is a relationship between indium compound exposure and interstitial lung damage in workers employed at indium tin oxide manufacturing and reclaiming factories in Korea.

Methods: In 2012, we conducted a study for the prevention of indium induced lung damage in Korea and identified 78 workers who had serum indium or Krebs von den Lungen-6 (KL-6) levels that were higher than the reference values set in Japan ( $3 \mu \mathrm{g} / \mathrm{L}$ and $500 \mathrm{U} / \mathrm{mL}$, respectively). Thirty-four of the 78 workers underwent chest high-resolution computed tomography (HRCT), and their data were used for statistical analysis.
\end{abstract}

Results: Geometric means (geometric standard deviations) for serum indium, KL-6, and surfactant protein D (SP-D) were 10.9 (6.65) $\mathrm{mg} / \mathrm{L}, 859.0(1.85) \mathrm{U} / \mathrm{mL}$, and 179.27 (1.81) ng/mL, respectively. HRCT showed intralobular interstitial thickening in 9 workers. A dose-response trend was statistically significant for blood KL-6 levels. All workers who had indium levels $\geq 50 \mu \mathrm{g} / \mathrm{L}$ had KL-6 levels that exceeded the reference values. However, dose-response trends for blood SP-D levels, KL-6 levels, SP-D levels, and interstitial changes on the HRCT scans were not significantly different.

Conclusions: Our findings suggest that interstitial lung changes could be present in workers with indium exposure. Further studies are required and health risk information regarding indium exposure should be communicated to workers and employers in industries where indium compounds are used to prevent indium induced lung damage in Korea.

Keywords: Indium, Interstitial lung disease, Occupational exposure

\section{Introduction}

Although pneumoconiosis is still the best-known occupational chronic lower airway disease, industrial developments in recent years have introduced new manufacturing materials and production methods, which have been identified as new causes of occupational interstitial lung disease. Nylon flock and diacetyl used in the flavor industry as well as indium compounds were shown to have an association with lower airway diseases [1].

Hardly soluble indium compounds such as indium oxide, indium zinc oxide, and indium tin oxide are used in the manufacturing of electrically conductive film for liquid crystal display (LCD) panels.

\footnotetext{
* Correspondence: toxneuro@kosha.net

'Occupational Safety and Health Research Institute, Korea Occupational Safety and Health Agency, Incheon, Republic of Korea

Full list of author information is available at the end of the article
}

Since the first report of a case of indium induced interstitial lung disease in 2003, [2] 7 other cases of indium induced interstitial lung disease were identified in Japan. In addition, 2 cases of pulmonary alveolar proteinosis (PAP) were reported in workers employed at an indium processing facility in the United States, and 1 case of PAP was reported in an worker exposed to indium in China [3-5]. Interstitial and emphysematous lung damage in workers who had been exposed to indium compounds are called "Indium Lung" [6]. Ten cases of indium lung disease as well as epidemiological studies suggest that hardly soluble indium compounds cause interstitial lung disease in workers who handle indium compounds [6-9].

Animal experiments showed that intratracheal instillation or inhalation of indium compounds result in pulmonary fibrosis [10-13]. The United States National Toxicology Program (NTP) conducted a 2-year long

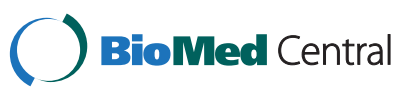

(C) 2013 Choi et al.; licensee BioMed Central Ltd. This is an open access article distributed under the terms of the Creative Commons Attribution License (http://creativecommons.org/licenses/by/2.0), which permits unrestricted use, distribution, and reproduction in any medium, provided the original work is properly cited. 
inhalation study of indium phosphide (InP) in mice and rats and concluded that there was clear evidence that InP is carcinogenic [14]. In 2006, the International Agency For Research On Cancer (IARC) classified InP as a probable carcinogenic agent in humans (Group 2A) [15]. Despite evidence of the harmful respiratory effects of indium compounds, there has not yet been any studies that investigated the incidence of indium induced interstitial lung disease in Korea. Therefore, this study was performed to assess whether there is a relationship between exposure to indium compounds and interstitial lung damage in workers exposed to indium compounds in Korea.

\section{Materials and methods Study subjects}

This study was approved by the ethics committee of Occupational Safety and Health Research Institute (OSHRI), Korea Occupational Safety and Health Agency (KOSHA), Incheon, Korea and conducted in accordance with the declaration of Helsinki.

In total, 301 workers who handled indium compounds in the course of their work, volunteered for the study for the prevention of indium lung disease in Korea at 2012 conducted by OSHRI of KOSHA. The serum indium or Krebs von den Lungen-6 (KL-6) concentrations of 78 workers exceeded the Japanese reference values $(3 \mu \mathrm{g} / \mathrm{L}$ and $500 \mathrm{U} / \mathrm{mL}$, respectively) [16]. Among them, 34 workers (43.6\%) agreed to undergo chest high-resolution computed tomography (HRCT), and the data of these workers were used for our statistical analysis. Health check items included completion of the OSHRI-developed questionnaire with past medical, job, and smoking histories as well as chest symptoms and signs, chest physical examinations, and spirometry as well as serum indium, KL-6, and surfactant protein D (SP-D) levels. SP-D was not used screening health check item to determine for Chest HRCT. Because Usefulness of SP-D in diagnosis of indium induced interstitial lung disease was not as good as KL-6 [6-8], and it had been listed one of secondary health check items for prevention of indium lung disease in Japan.

An occupational physician interviewed each of the workers and confirmed the accuracy of the information on the questionnaires.

\section{Spirometry}

Spirometry was performed using $\mathrm{PC}-10$ spirometer (CHEST M.I., Inc., Tokyo, Japan) to get forced vital capacity (FVC) and forced expiratory volume 1 second/ forced vital capacity (FEV1/FVC). In the sitting position, the tests were repeated until obtaining appropriate and reproducible results at least three times, and then the best results were selected. All results were confirmed by physician.

\section{Serum KL-6 and SP-D}

KL-6 is a mucin-like high molecular glycoprotein, which is strongly expressed on alveolar type II pneumocyte [17]. Serum KL-6 has been known one of sensitive biomarker for interstitial lung diseases such as idiopathic pulmonary fibrosis, radiation pneumonitis, connective tissue disease-associated interstitial lung disease, lung involvement of sarcoidosis, and pulmonary alveolar proteinosis $[18,19]$.

SP-D is produced and secreted by type II pneumocyte. It is also elevated in patient with inflammatory lung diseases, including idiopathic pulmonary fibrosis and pulmonary alveolar proteinosis $[20,21]$.

Serum KL-6 levels were measured by enzyme-linked immunosorbent assay (ELISA) kit (EIDIA Co., Ltd., Tokyo, Japan). And the concentration of serum SP-D was measured by human surfactant protein D ELISA kit (BioVendor, Brno, Czech). The methods and steps for analysis of KL-6 and SP-D were followed by guidelines presented by manufacturers. All samples for KL-6 and SP-D were analyzed twice, and mean values were reported and used for statistical analysis.

\section{HRCT scanning and radiologic evaluation}

Chest HRCT was performed at the 3 hospitals near the factories when serum indium or KL-6 levels exceeded the Japanese reference values. And then all HRCT films were reviewed by a chest radiology specialist, and the reports were discussed with occupational physician.

All of the subjects underwent volumetric thin section HRCT scan. Patients were scanned caudocranially in one breath hold; $1 \mathrm{~mm}$ collimation was used at a table feed of $6 \mathrm{~mm} / 0.75 \mathrm{~s}$ scanner rotation $(8 \mathrm{~mm} / \mathrm{s})$ at $120 \mathrm{kV}$ and $140 \mathrm{~mA}$. Scanning was performed from the lung bases toward the apices. The volumetric axial images with $1 \mathrm{~mm}$ thickness and the $1 \mathrm{~mm}$ intervals were reconstructed with a high spatial frequency algorithm on supine and prone position. The images were viewed at window levels of $-700 \mathrm{HU}$ for analysis of thin section HRCT features. All images were displayed at the lung window setting using a PACS (picture archiving and communication system) workstation (Deja-View, Dongeun Information technology).

The thin section HRCT scans were evaluated for the presence and/or extent of the following features to evaluate indium induced interstitial lung damage:

(1) interlobular or intralobular interstitial thickening; (2) area of ground glass opacity (GGO); (3) area of emphysema. These findings were defined according to the glossary of terms recommended by the Fleischner Society [22]. 
The lung was divided into six zones (upper, middle, and lower, right and left) by one third and two third of the vertical distance between the lung apices and the domes of the diaphragm. Each of these zones was evaluated and scored separately for the presence and/or extent of the features on the thin section HRCT scan. Interlobular and intralobular interstitial thickening were scored in each of six zones according to the subjective score of the involved area to cross sectional area $(0=$ no involvement; $1=$ minimal involvement; $2=$ moderate involvement; $3=$ severe involvement) as described in other studies [23,24]. The scores of the six zones were summated as the total scores for Interlobular and intralobular interstitial thickening from 0 to 18 . The remaining features of the thin section HRCT scan (ground glass opacity and emphysema) were evaluated in same scoring system for interlobular or intralobular interstitial thickening. They were expressed as a semi-quantitative scale of grade (score of interlobular and intralobular interstitial thickening + score of ground glass opacity + score of emphysema) as follows: grade $0,<1$; grade $1,1-5$; grade $2,6-10$; grade $3,11-15$; grade $4,>16$.

Cases of grade 1 or more were regarded positive interstitial changes, grade 0 or other suspected cases were regarded negative.

\section{Statistical analysis}

We assessed whether continuous data were normally distributed, and data sets that were not normally distributed were log-transformed before analysis. Mean values of variables were calculated and compared with $t$-tests or ANOVA, where appropriate. Prevalence data were compared using chi-square test, Fisher's exact tests, and Mantel-Haenszel trend test.

To compare KL-6 and SP-D levels between groups with low and high serum indium levels, the 34 subjects were divided in 2 groups: subject with serum indium levels of $<10 \mu \mathrm{g} / \mathrm{L}(\mathrm{S}$-in $<10)$ and those with $\geq 10 \mu \mathrm{g} / \mathrm{L}$ ( $\mathrm{S}$-in $\geq 10$ ) were grouped together. Serum indium level of $10 \mu \mathrm{g} / \mathrm{L}$ was simple cut-off value in considering of number of subjects, to divide groups low and high serum indium levels. And To analyze the dose-response relationship between serum indium levels and KL-6 levels, SP-D levels, and HRCT finding, the workers were classified into 6 groups according to their serum indium levels (group 0: less than 1.0, group 1: 1.0-4.9, group 2: 5.0-9.9, group 3: 10.0-29.9, group 4: 30.0-49.9, and group 5 : $\geq 50.0$ ). $P$ values $<0.05$ were considered statistically significant.

\section{Results}

Characteristics of the study subjects

Table 1 shows the characteristics of the study subjects. Eighteen of the workers were employed in the indium
Table 1 Characteristics of study subjects

\begin{tabular}{llc}
\hline Characteristics & $\begin{array}{c}\text { Number of } \\
\text { subjects (\%) }\end{array}$ \\
\hline $\mathrm{n}$ & & 34 \\
Age (yr): Mean (range) & $34.7(20-59)$ \\
Sex & Male & $29(85.3)$ \\
& Female & $5(14.7)$ \\
Smoking & Currant smoker & $15(44.1)$ \\
& Ex-smoker & $16(47.1)$ \\
& Never smoker & $3(8.8)$ \\
Exposure duration (mo): & & $43.4(3-120)$ \\
mean (range) & & $18(52.9)$ \\
Workplace & ITO production & $16(47.1)$ \\
\hline
\end{tabular}

ITO: indium tin oxide.

tin oxide (ITO) production industry, and the remaining 16 workers were employed at recycling plants. The average age of the 34 workers was 34.7 years (range, 20-59 years): 29 were men and 5 were women. The mean duration of indium exposure for the group was 43.4 months. Fifteen were current smokers, and 16 of the 19 non-current smokers had a history of smoking. Table 2 shows the medical history of our study subjects. Thirty-two of the 34 workers did not have a history of cardiopulmonary disease, whilst 2 had a history of hypertension.

\section{Chest symptoms and chest physical examination}

The questionnaire assessed chest symptoms and included questions regarding symptoms of cough, sputum, chest discomfort, palpitation, and wheezing. Sixteen of the 34 workers did not experience any of these symptoms, whilst 18 of the workers experienced at least 1 of the 5 chest symptoms. The prevalence rate of respiratory symptoms was higher amongst current smokers than amongst non-current smokers, but statistical significance was not reached (Table 3). The chest physical examination results of all 34 workers were normal.

Table 2 The medical history of the study subjects

\begin{tabular}{lcc}
\hline Past medical history & N & $\%$ \\
\hline None & 32 & 94.1 \\
Pulmonary tuberculosis & 0 & 0 \\
Pneumonia & 0 & 0 \\
Asthma & 0 & 0 \\
COPD & 0 & 0 \\
Hypertension & 2 & 5.9 \\
Diabetes mellitus & 0 & 0 \\
Heart disease & 0 & 0 \\
Total & 34 & 100.0 \\
\hline
\end{tabular}

Abbreviations: $N$ number of subjects, COPD chronic obstructive pulmonary disorder. 
Table 3 Respiratory symptoms

\begin{tabular}{|c|c|c|c|c|c|c|c|}
\hline \multirow[b]{2}{*}{ Respiratory symptoms } & \multicolumn{2}{|c|}{$\begin{array}{c}\text { Current } \\
\text { smokers }\end{array}$} & \multicolumn{2}{|c|}{$\begin{array}{l}\text { Ex or never } \\
\text { smoked }\end{array}$} & \multicolumn{2}{|c|}{ Total } & \multirow[t]{2}{*}{$\mathbf{p}$} \\
\hline & $\mathrm{N}$ & $\%$ & $\mathrm{~N}$ & $\%$ & $\mathbf{N}$ & $\%$ & \\
\hline No & 5 & 33.3 & 11 & 57.9 & 16 & 47.1 & 0.1542 \\
\hline \multirow[t]{2}{*}{ Yes } & 10 & 66.7 & 8 & 41.1 & 18 & 52.9 & \\
\hline & & & & & 34 & & \\
\hline
\end{tabular}

Abbreviations: $N$ number of subjects, $P$ probability by Chi-square test, Respiratory symptoms: at least one or more symptoms of cough, sputum, chest discomfort, palpitation, and wheezing.

\section{Serum immunochemistry, spirometry, and chest HRCT}

Table 4 shows the results of the serum immunochemistry. Geometric means (GM) and geometric standard deviations (GSD) of serum indium, KL-6, and SP-D in the workers were 10.9 (6.7) $\mu \mathrm{g} / \mathrm{L}, 859.0$ (1.9) U/mL, and $179.3(1.8) \mathrm{ng} / \mathrm{mL}$, respectively.

The GM of KL- 6 in group $S$-in $<10$ and in group $\mathrm{S}$-in $\geq 10$ were $704.4 \mathrm{U} / \mathrm{mL}$ and $1024.6 \mathrm{U} / \mathrm{mL}$, respectively, and the GM of SP-D in group S-in $<10$ and S-in $\geq 10$ was $135.0 \mathrm{ng} / \mathrm{mL}$ and $230.7 \mathrm{ng} / \mathrm{mL}$, respectively. Although the GM of KL-6 and SP-D for subjects with S-in $\geq 10$ were higher than that for subjects with $\mathrm{S}$-in $<10$, only SP-D levels differed significantly between groups, whilst differences in KL-6 levels did not reach significance.

The $\mathrm{FEV}_{1} / \mathrm{FVC}$ ratio of all 34 workers was within the normal range of $>70 \%$, whilst the $\%$ FVC were within the normal range of $>80 \%$ for all except 2 workers. These 2 workers had \% FVC values of $73.4 \%$ and $78.8 \%$, respectively, and each of them had mild restrictive patterns. Nine of the 34 workers had evidence of interstitial changes on chest HRCT (Grade 1: 3 cases, Grade 2: 4 cases, Grade 3: 2 cases). The main HRCT findings were intralobular interstitial thickening, whilst there were no workers with ground glass opacities or emphysematous changes.

GM and GSD of KL-6 and SP-D, prevalence (\%) for exceeding the reference values of KL-6 and SP-D, and

\section{Table 4 Serum immunochemistry}

\begin{tabular}{lccccc}
\hline Serum immunochemistry & $\mathbf{n}$ & GM & GSD & Range & $\mathbf{p}$ \\
\hline Serum indium $(\mu \mathrm{g} / \mathrm{L})$ & 34 & 10.9 & 6.7 & ND-125.8 & \\
S-in $<10$ & 16 & 2.5 & 6.2 & ND-9.2 & $<0.0001$ \\
S-in $\geq 10$ & 18 & 39.4 & 2.2 & $11.7-125.8$ & \\
KL-6 $(\mathrm{U} / \mathrm{mL})$ & 34 & 859.0 & 1.9 & $274.6-2062.2$ & \\
S-in $<10$ & 16 & 704.4 & 1.8 & $242.6-942.7$ & 0.0760 \\
S-in $\geq 10$ & 18 & 1024.6 & 1.8 & $948.0-2062.2$ & \\
SP-D $(\mathrm{ng} / \mathrm{mL})$ & 34 & 179.3 & 1.8 & $60.0-466.1$ & \\
S-in $<10$ & 16 & 135.0 & 1.7 & $59.9-177.0$ & 0.0064 \\
S-in $\geq 10$ & 18 & 230.7 & 1.7 & $183.4-466.1$ & \\
\hline
\end{tabular}

Abbreviations: GM geometric mean, GSD geometric standard deviation, $S$-in serum indium, $K L-6$ Krebs von den Lungen-6, SP-D surfactant protein $D$, $\mathrm{P}$ probability by Student $t$-test. interstitial changes on chest HRCT in each group are shown in Table 5. Dose-dependent trends for KL-6 and SP-D were statistically significant when age- and smokingadjusted multiple regression model was applied. 5.40+ 0.1360* serum indium for KL-6 $(\mathrm{p}=0.0055)$ and $5.25+$ $0.1846 *$ serum indium for SP-D $(\mathrm{p}=0.0005)$. Results of Dunnett's test revealed that compared to Group 0, the means KL-6 value of groups 4 and 5 increased significantly. Mean values of SP-D increased in patients with serum indium levels $\geq 10 \mu \mathrm{g} / \mathrm{L}$, but statistical significance was not reached. The KL-6 levels of all 12 workers in Group 4 and 5 were above the reference value. A doseresponse trend for the prevalence of SP-D, but not for the prevalence of KL-6 and interstitial changes on HRCT, was statistically significant. The prevalence of these changes on the HRCT in each group was not significantly different $(0.0 \%-42.9 \%)$ (Figure 1).

\section{Discussion}

In this study we did not clarify the dose-effect and doseresponse relations between indium compound exposure and interstitial lung changes on HRCT. However, we found significant dose-effect and dose-response relations between serum indium levels and GM of KL-6 and the prevalence of exceeding reference value of SP-D in workers exposed to indium, despite of the insignificant difference of the prevalence of exceeding reference value of KL-6 and HRCT. Although we did not include non-exposed individuals in our study, our results clearly show that the GM of KL-6 and SP-D levels were higher in workers with serum indium levels $\geq 10 \mathrm{ug} / \mathrm{L}$ than in those with serum indium levels $<10 \mathrm{ug} / \mathrm{L}$.

Our finding showed similar results the studies of Japan [7-9] reported that workers exposed to indium compounds had significantly higher serum indium, KL-6, and SP-D levels than non-exposed workers. In addition, serum indium level was positively correlated with KL-6 and SP-D levels. The rates of exceeding reference value of serum indium, KL-6, and SP-D were statistically high in exposed workers. However, the prevalence of interstitial thickening on HRCT identified interstitial lung- and emphysematous changes in exposed workers were not significantly different from that in non-exposed workers. These studies reported dose-effect and dose-response relationships between serum indium and KL-6, SP-D, and HRCT, and found no significant differences in KL-6 and SP-D levels between current smokers and noncurrent smokers.

Insignificant relationship of KL-6 and HRCT in this study might be influenced by the limited number of the study subjects. Because relatively small number of the workers having high level of KL-6 had volunteered for HRCT (43.6\%) when compared with that in previous studies, the participants might be influenced by selection 
Table 5 Dose-response relations between serum indium and KL-6, SP-D, and interstitial changes on chest HRCT

\begin{tabular}{|c|c|c|c|c|c|c|c|c|c|c|}
\hline \multirow[b]{2}{*}{ Group } & \multicolumn{3}{|c|}{ Serum indium $(\mu \mathrm{g} / \mathrm{L})$} & \multicolumn{2}{|c|}{$\mathrm{KL}-6(\mathrm{U} / \mathrm{mL})$} & \multicolumn{2}{|c|}{ SP-D (ng/mL) } & \multicolumn{3}{|c|}{ Prevalence (\%) } \\
\hline & Range & GM & $\mathrm{n}$ & GM & GSD & GM & GSD & $\mathrm{KL}-6(>500 \mathrm{U} / \mathrm{mL})$ & SP-D (>110 ng/mL) & HRCT-I \\
\hline 0 & $<1.0$ & 0.2 & 3 & 586.1 & 1.3 & 120.9 & 2.9 & 100.0 & 33.3 & 0.0 \\
\hline 1 & $1.0-4.9$ & 3.4 & 7 & 509.6 & 1.7 & 143.8 & 1.5 & 42.9 & 71.4 & 14.3 \\
\hline 2 & $5.0-9.9$ & 7.4 & 6 & 1126.9 & 1.6 & 132.5 & 1.6 & 83.3 & 66.7 & 33.3 \\
\hline 3 & $10.0-29.9$ & 15.5 & 6 & 486.3 & 1.4 & 157.6 & 1.6 & 50.0 & 83.3 & 16.7 \\
\hline 4 & $30.0-49.9$ & 43.8 & 5 & $1539.4^{*}$ & 1.5 & 252.6 & 1.9 & 100.0 & 80.0 & 40.0 \\
\hline 5 & $\geqq 50$ & 81.5 & 7 & $1451.1^{*}$ & 1.1 & 299.8 & 1.3 & 100.0 & 100.0 & 42.7 \\
\hline$p$ for trend & & & & 0.0055 & & 0.0005 & & 0.1057 & 0.0353 & 0.1198 \\
\hline
\end{tabular}

Abbreviations: GM geometric mean, GSD geometric standard deviation, KL-6 Krebs von den Lungen-6, SP-D surfactant protein D, HRCT-I interstitial changes on $\mathrm{HRCT}$, Prevalence (\%): \% of workers exceeding each reference values and \% of workers with interstitial changes on $\mathrm{HRCT}, \mathrm{p}$ for trend: age- and smoking-adjusted multiple regression model for GM and GSD of KL- 6 and SP-D, Mantel-Haenszel trend for prevalence data, * $\mathrm{P}<0.05$ by Dunnett's test.

bias, and this could affect to the unclear dose-effect and dose-response relations for all parameters of this study. This study was conducted for screening interstitial lung disease and gathering basic health information in indium exposed workers, so interstitial lung damages were not confirmed pathologically. There were no statistical differences in the prevalence of KL-6, SP-D, and interstitial changes as seen on HRCT between current smokers and non-current smokers (data not shown).

The pathogenesis of indium related lung disorder is not understood yet. According to the 2001 NTP report, [14] the incidence of adenoma and lung cancer increased in laboratory rats and mice exposed to InP, and the extent and severity of inflammatory lesions were much greater and included atypical hyperplasia, chronic inflammation, alveolar epithelial hyperplasia and metaplasia, alveolar proteinosis, and interstitial fibrosis. In the same manner, the reported cases related with indium found various clinical syndromes. Interstitial thickening and emphysematous changes in the lungs, as seen on HRCT, were evident in 7 patients who worked in grinding process of indium tin oxide target manufacturing factory of indium lung disease in Japan. However, 2 patients worked in reclaiming facility in the United States and 1 patient in China who was exposed to indium compound in display production.

Interstitial lung fibrosis cases in Japan showed intraalveolar filling of cholesterol crystal, which is pathological

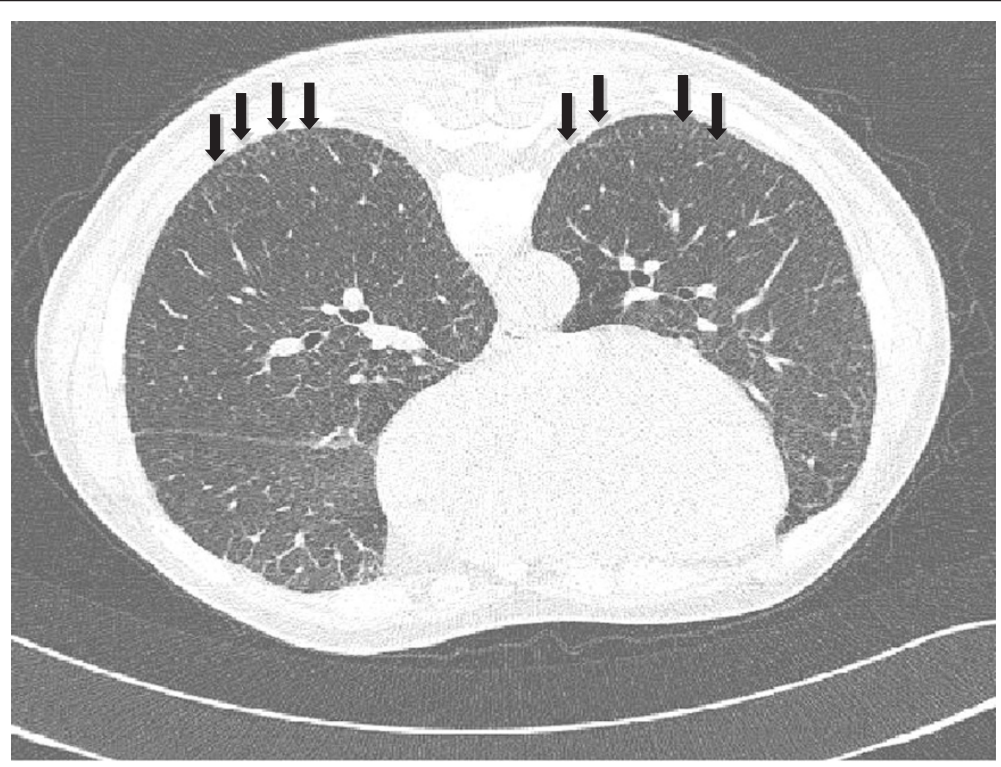

Figure 1 High-resolution computed tomography scans on prone position of a worker with no history of smoking, who had been employed at an indium tin oxide target production facility for 7 years (sintering room for 4 years and indium oxide powder room for 3 years). The image shows subpleural interlobular interstitial thickening in both lower lung fields (arrows). The patient had no history of respiratory diseases. Results of health examinations were as follows: serum indium, 50 mg/L; KL-6, $1769 \mathrm{U} / \mathrm{mL}$; FVC, 86\% predicted; FEV1/FVC, 109.6\% predicted. 
features of pulmonary alveolar proteinosis. The pulmonary lesion of Japanese cases were not only confined in intraalveolar space, but also infiltrated interstitium. Thus, Japanese cases may represent pulmonary alveolar proteinosis with interstitial involvement [4].

The pathogenesis of indium toxicity is not clear. Therefore, the reasons underlying the different pathologic findings after indium exposure remain unclear. One hypothesis that could explain the pathogenesis of indium lung disease is the notion that indium induces a "foreign body reaction" $[4,5]$. This hypothesis suggests that when indium compounds are inhaled into the lungs, a foreign body reaction and macrophage dysfunction in the lungs are induced, leading accumulation of intraalveolar lipoproteinaceous material and development of cholesterol ester crystals with the formation of cholesterol granulomas and this results in eventual interstitial fibrosis and emphysema. However, this hypothesis does not sufficiently explain the pathologic findings of fibrotic foci in areas without cholesterol ester crystals. Other undiscovered pathogenic mechanisms for indium lung disease may exist.

Tin is a well-known cause of stannosis, benign pneumoconiosis without fibrosis, or necrosis $[25,26]$. Previous animal experiments [6-9,14] and an epidemiological study [8] reported that tin-free indium compounds induced lung fibrosis. It is thought that pulmonary interstitial fibrosis in workers exposed to indium tin oxide could be attributed to indium compounds.

We used serum indium levels as a biological exposure index for indium compound exposure in this study. Based on the 2001 NTP report, [14] serum indium levels increased proportionally with an increase in the duration of exposure, although serum indium levels were low relative to indium concentrations in the lungs. And the decrease in serum indium levels was slower than indium clearance in the lungs. KL-6 and SP-D were used as an index to evaluate pulmonary interstitial damages. But biological half-life of indium compound was not been defined clearly.

Workers enrolled in our study were from different indium processing facilities in different parts of Korea, and it was therefore not possible for us to perform chest HRCT in 1 hospital only. Therefore, the quality of chest HRCT may not have been uniform.

\section{Conclusion}

In Korea, the demand for indium compounds increased with the expansion of the display manufacturing industry, but the extent to which indium is used in this country remains unclear. In 2011, the domestic demand for indium in Korea was estimated to be 950 tons [27]. This estimate was similar to the amount used in Japan in 2006 [6]. According to this estimation, Korea is one of the foremost consumers of indium in the world. Although our study had some limitations, to our knowledge, it is the first investigation of indium induced interstitial lung damage in Korea, and our results are meaningful as an initial step in the identification and prevention of indium induced lung damage in Korea. Nakano et al. [7] investigated serum indium, KL-6, and SP-D levels before and after engineering control, which included the use of appropriate respiratory protective devices, improvement of workplace ventilation and found that serum indium, KL-6, and SP-D levels decreased after these improvements. Further studies are required to clarify pathogenesis of indium induced interstitial lung damage. Health risk information regarding indium exposure should be communicated to workers and employers in industries where indium compounds are used to prevent indium induced lung damage in Korea.

\section{Consent}

Written informed consent was obtained from all the workers for the publication of this report and any accompanying images.

\section{Competing interests}

The authors declare that they have no competing interests.

\section{Authors' contributions}

CSY and KEA conceived and designed the study. KDH, CSY, YGY and WYI were involved in conduction of the study. YGY measured the environmental exposure and WYL performed the analysis of the biological index. PJS conducted imaging study. KEA, CSY and KDH interpretation of data. All authors read and approved the final manuscript.

\section{Author details}

'Occupational Safety and Health Research Institute, Korea Occupational Safety and Health Agency, Incheon, Republic of Korea. ${ }^{2}$ Department of Radiology, Soonchunhyang University Bucheon Hospital, Bucheon, Republic of Korea.

Received: 12 June 2013 Accepted: 10 October 2013

Published: 21 October 2013

\section{References}

1. Sauler M, Gulati M: Newly recognized occupational and environmental causes of chronic terminal airways and parenchymal lung disease. Clin Chest Med 2012, 33:667-680.

2. Homma T, Ueno T, Sekizawa K, Tanaka A, Hirata M: Interstitial pneumonia developed in a worker dealing with particles containing indium-tin oxide. J Occup Health 2003, 45:137-139.

3. Homma S, Miyamoto A, Sakamoto S, Kishi K, Motoi N, Yoshimura K: Pulmonary fibrosis in an individual occupationally exposed to inhaled indium-tin oxide. Eur Respir J 2005, 25:200-204.

4. Cummings KJ, Donat WE, Ettensohn DB, Roggli VL, Ingram P, Kreiss K: Pulmonary alveolar proteinosis in workers at an indium processing facility. Am J Respir Crit Care Med 2010, 181:458-464.

5. Cummings KJ, Nakano M, Omae K, Takeuchi K, Chonan T, Xiao YL, Harley RA, Roggli VL, Hebisawa A, Tallaksen RJ, et al: Indium lung disease. Chest 2012, 141:1512-1521.

6. Omae K, Nakano M, Tanaka A, Hirata M, Hamaguchi T, Chonan T: Indium lung-case reports and epidemiology. Int Arch Occup Environ Health 2011, 84:471-477.

7. Nakano M, Omae K, Tanaka A, Hirata M, Michikawa T, Kikuchi Y, Yoshioka N, Nishiwaki Y, Chonan T: Causal relationship between indium compound inhalation and effects on the lungs. J Occup Health 2009, 51:513-521. 
8. Hamaguchi T, Omae K, Takebayashi T, Kikuchi Y, Yoshioka N, Nishiwaki Y, Tanaka A, Hirata M, Taguchi O, Chonan T: Exposure to hardly soluble indium compounds in ITO production and recycling plants is a new risk for interstitial lung damage. Occup Environ Med 2008, 65:51-55.

9. Chonan T, Taguchi O, Omae K: Interstitial pulmonary disorders in indiumprocessing workers. Eur Respir J 2007, 29:317-324.

10. Blazka ME, Dixon D, Haskins E, Rosenthal GJ: Pulmonary toxicity to intratracheally administered indium trichloride in Fischer 344 rats. Fundam Appl Toxicol 1994, 22:231-239.

11. Kabe I, Omae K, Nakashima H, Nomiyama T, Uemura T, Hosoda K, Ishizuka C, Yamazaki K, Sakurai H: In vitro solubility and in vivo toxicity of indium phosphide. J Occup Health 1996, 38:6-12.

12. Oda K: Toxicity of a low level of indium phosphide $(\operatorname{InP})$ in rats after intratracheal instillation. Ind Health 1997, 35:61-68.

13. Uemura T, Oda K, Omae K, Takebayashi T, Nomiyama T, Ishizuka C, Hosoda K, Sakurai $\mathrm{H}$, Yamazaki K, Kabe I: Effects of intratracheally administered indium phosphide on male Fischer 344 rats. J Occup Health 1997, 39:205-210.

14. National Institutes of Health: Toxicology and carcinogenesis studies of indium phosphide (CAS No. 22398-90-7). In F344/N rats and B6C3F1 mice (inhalation studies), National toxicology program technical report series. NC. $\mathrm{NIH} ; 2001: 7-340$.

15. IARC: Cobalt in hard metals and cobalt sulfate, gallium arsenide, indium phosphide and vanadium pentoxide. IARC Monogr Eval Carcinog Risks Hum 2006, 86:1-294.

16. Nakajima M, Manabe T, Niki Y, Matsushima T: Serum KL-6 level as a monitoring marker in a patient with pulmonary alveolar proteinosis. Thorax 1998, 53:809-811.

17. Kobayashi J, Kitamura S: KI-6: a serum marker for interstitial pneumonia. Chest J 1995, 108:311-315.

18. Kobayashi M, Takeuchi T, Ohtsuki Y: Differences in the immunolocalization of surfactant protein (SP)-a, SP-D, and KL-6 in pulmonary alveolar proteinosis. Pathol Int 2008, 58:203-207.

19. Bonella F, Ohshimo S, Miaotian C, Griese M, Guzman J, Costabel U: Serum $\mathrm{KL}-6$ is a predictor of outcome in pulmonary alveolar proteinosis. Orphanet I Rare Dis 2013, 8:53.

20. Greene KE, King TE, Kuroki Y, Bucher-Bartelson B, Hunninghake GW, Newman LS, Nagae H, Mason RJ: Serum surfactant proteins-A and -D as biomarkers in idiopathic pulmonary fibrosis. Eur Respir J 2002, 19:439-446.

21. Kuroki Y, Tsutahara S, Shijubo N, Takahashi H, Shiratori M, Hattori A, Honda $Y$, Abe S, Akino T: Elevated levels of lung surfactant protein a in sera from patients with idiopathic pulmonary fibrosis and pulmonary alveolar proteinosis. Am Rev Respir Dis 1993, 147:723-729.

22. Austin JH, Muller NL, Friedman PJ, Hansell DM, Naidich DP, Remy-Jardin M, Webb WR, Zerhouni EA: Glossary of terms for CT of the lungs: recommendations of the nomenclature committee of the fleischner society. Radiology 1996, 200:327-331.

23. Jensen SP, Lynch DA, Brown KK, Wenzel SE, Newell JD: High-resolution CT features of severe asthma and bronchiolitis obliterans. Clin Radiol 2002. 57:1078-1085.

24. Hansell DM, Wells AU, Rubens MB, Cole PJ: Bronchiectasis: functional significance of areas of decreased attenuation at expiratory CT. Radiology 1994, 193:369-374.

25. Stewart JH, Lassiter DV: Germanium, tin, and copper. Patty's Toxicol 2001, Vol1:335-383.

26. Sluis-Cremer GK, Thomas RG, Goldstein B, Solomon A: Stannosis. A report of 2 cases. S Afr Med J 1989, 75:124-126.

27. Ishikawa N, Kondo K, Oguri T, Kamitsuna M, Sakurai J, Fujitaka K, Yamasaki M, Maeda H, Isobe T, Kohno N: Usefulness of the modified lavage technique of bingisser and KL-6 monitoring in a patient with pulmonary alveolar proteinosis. Intern Med 2002, 41:381-385.

doi:10.1186/2052-4374-25-24

Cite this article as: Choi et al: Subclinical interstitial lung damage in workers exposed to indium compounds. Annals of Occupational and Environmental Medicine 2013 25:24.

\section{Submit your next manuscript to BioMed Central and take full advantage of:}

- Convenient online submission

- Thorough peer review

- No space constraints or color figure charges

- Immediate publication on acceptance

- Inclusion in PubMed, CAS, Scopus and Google Scholar

- Research which is freely available for redistribution

Submit your manuscript at www.biomedcentral.com/submit
C Biomed Central 